\title{
PERMAINAN LEMPAR DADU SEBAGAI MEDIA PEMBELAJARAN BINA DIRI KESEHATAN ANAK DOWN SYNDROMEE
}

\author{
Yovita Eka Ratna Kumala, Wafi Nur Muslihatun
}

\author{
Jurusan Kebidanan Poltekkes Kemenkes Yogyakarta \\ Email: wafinuranwar@gmail.com
}

\begin{abstract}
Down syndrome is a genetic disorder known as trisomy 21 and is most common. Down syndrome children have visual processing skills are better, but almost all children who suffer from this disorder can not read, write and take care of herself. This study aims to prove whether Roll dice game method can improve the ability of children with Down syndrome do Bina Yourself Healthy at SLB Mardi Mulya Kretek, Bantul, Yogyakarta. This study is a game of throwing dice experiment with the design of one group pretest-posttest. The instruments used were throwing dice game instruction with the words, cartoons and images and test viewing capabilities and perform the instructions mentioned on the dice. Data were analyzed descriptively calculate the percentage of children's success. The results showed toss the dice with the instructions of the original image (photo) provides the capability to mention children and do the instruction with the highest success rate (95.23\%) compared to the instruction by writing (14.28\%) and cartoons (66.67\%).
\end{abstract}

Keywords: toss the dice, children with down syndrome

\section{PENDAHULUAN}

Down Syndrome merupakan kelainan genetik yang dikenal sebagai trisomi 21, karena individu yang mengalami down Syndrome memiliki kelebihan satu kromosom pada kromosom ke-21. Anak down Syndrome mempunyai tiga kromosom 21, sementara orang normal hanya mempunyai dua saja. Kelebihan kromosom ini akan mengubah keseimbangan genetik tubuh dan mengakibatkan perubahan karakteristik fisik dan kemampuan intelektual, serta gangguan dalam fungsi fisiologi tubuh ${ }^{1}$. Down syndrome merupakan kelainan genetik yang paling sering terjadi dengan angka kejadian secara umum adalah satu di antara 650-1.000 orang. Kelainan ini bersifat universal, tidak mengenal batas ras, bangsa, suku bangsa, geografi, musim dan jenis kelamin. Insiden kelainan kromosom seperti trisomi 21 (Down Syndrome) meningkat dengan meningkatnya usia maternal ${ }^{2}$. Menurut Indonesian Center for Biodiversity and Biotechnology (ICBB) Bogor, di Indonesia terdapat 300 ribu anak anak menderita Down Syndrome dan terdapat delapan juta anak di dunia menderita Down Syndrome ${ }^{3}$ Penanganan UNICEF terhadap down syndrome masuk dalam peringkat enam dunia. Hal ini menunjukkan bahwa penderita down syndrome semakin banyak dan membutuhkan penanganan dan tindakan lebih lanjut ${ }^{4}$.

Anak down syndrome memiliki keadaan berbeda dengan anak normal lain. Anak dengan down syndrome memiliki suatu kondisi keterbelakangan perkembangan fisik dan mental. Hal tersebut disebabkan karena abnormalitas dalam perkembangan kromosom selama kehamilan berlangsung. Anak down Syndrome memiliki tingkat kecerdasan IQ sekitar 30-50. Seorang anak yang menderita down Syndrome mengalami keterlambatan dalam menerima pelajaran akibat kesulitan dalam membaca, menulis, dan menerima ilmu. Anak dengan down syndrome memiliki visual processing skills yang lebih baik, tetapi hampir semua anak yang menderita kelainan ini tidak dapat membaca, menulis dan merawat dirinya sendiri. Anak down syndrome mempunyai permasalahan dan kebutuhan yang memerlukan pelayanan khusus agar dapat berkembang optimal sehingga pada akhirnya dapat hidup layak di tengah masyarakat. Bagi anak normal persoalan mengurus diri sendiri dapat dipelajari dengan mudah melalui instingtif, sedangkan bagi anak down syndrome persoalan 
merawat diri sendiri harus terprogram secara rinci. Melalui latihan merawat diri sendiri pada pelajaran Bina Diri anak down syndrome diarahkan untuk mengaktualisasikan dan mengembangkan kemampuan dalam melakukan aktivitas hidup sehari-hari memenuhi kebutuhan dirinya sendiri sehingga tidak membebani orang lain. Salah satu kompetensi dalam kurikulum pembelajaran bina diri pada aspek merawat diri sendiri adalah menjaga kesehatan ${ }^{5}$. Kondisi di lapangan menunjukkan bahwa motivasi belajar dan kemampuan merawat diri sendiri anak down syndrome masih rendah di SLB. Aktivitas menggosok gigi pada anak-anak dengan down syndrome masih dibantu guru maupun orangtuanya. Anak belum mampu melakukannya secara mandiri dan atas inisiatif sendiri. Penelitian ini bertujuan untuk membuktikan apakah metode permaian dengan menggunakan Lempar Dadu dapat meningkatkan kemampuan anak down syndrome melakukan Bina Diri di SLB Mardi Mulya Kretek Bantul Yogyakarta.

\section{METODE PENELITIAN}

Penelitian ini merupakan penelitian eksperimen (memberikan perlakuan) dengan desain One Group pretest-posttest ${ }^{6}$ pada anak kelas VI di SLB Mardi Mulya Kretek Bantul Yogyakarta. Besar sampel dalam penelitian ini adalah tujuh orang anak down syndrome, diambil dengan teknik total sampling pada siswa kelas VI tersebut. Variabel independen dalam penelitian ini adalah metode permainan lempar dadu. Variabel dependen dalam penelitian ini adalah kemampuan anak merawat diri sendiri.

Alat pengumpulan data yang digunakan dalam penelitian ini adalah tes kemampuan bina diri kesehatan anak down syndrome. Tes ini untuk melihat kemampuan menyebutkan dan melakukan instruksi yang ada pada sisi dadu yang dilempar oleh anak sendiri. Data dikumpulkan langsung oleh peneliti dengan melihat kemampuan anak menyebutkan dan melakukan instruksi dengan tiga macam intervensi/perlakuan. Setelah data diperoleh, selanjutnya dilakukan analisis data secara deskriptif dengan menghitung persentase kemampuan anak merawat diri. Hal utama yang dilakukan dalam menganalisis data hasil penelitian kasus tunggal antara lain membuat grafik, menggunakan statistik deskriptif dan analisis visual ${ }^{7}$.

\section{HASIL DAN PEMBAHASAN \\ Hasil}

Hasil penelitian menunjukkan bahwa tujuh anak down syndrome mempunyai karakteristik yang hampir sama, meliputi meliputi jenis ketunaan, usia, pekerjaan orang tua (ayah dan ibu), seperti tercantum pada Tabel 1.

Tabel 1. Karakteristik Anak Down Syndrome yang Diberikan Perlakuan Lempar Dadu sebagai Media Pembelajaran Bina Diri Kesehatan di SLB Mardi Mulya Kretek Bantul Yogyakarta (N=7)

\begin{tabular}{cccccc}
\hline No. & Inisial & Ketunaan & Usia & Pekerjaan Ayah & Pekerjaan Ibu \\
\hline 1. & Anak R & Tunagrahita & 13 tahun & Petani & Petani \\
2. & Anak Ra & Tunagrahita & 12 tahun & Pedagang & Tidak Bekerja \\
\cline { 3 - 6 } 3. & Anak Ri & Tunagrahita & 15 tahun & Pedagang & Tidak Bekerja \\
4. & Anak V & Tunagrahita & 12 tahun & Kepolisian & Tidak Bekerja \\
5. & Anak Vt & Tunagrahita & 13 tahun & Petani & Petani \\
6. & Anak Ni & Tunagrahita & 12 tahun & PNS & Tidak Bekerja \\
7. & Anak Be & Tunagrahita & 15 tahun & Petani & Petani \\
\hline
\end{tabular}

Tabel 1. Menunjukkan bahwa ketujuh anak mempunyai jenis ketunaan yang sama yaitu tunagrahita. Berdasarkan karakteristik usia, usia paling muda adalah 12 tahun, usia paling tua adalah 15 tahun, dengan usia rata-rata 13,14 tahun. Berdasarkan karakteristik pekerjaan ayah, sebanyak $43 \%$ ayah bekerja sebagai petani, $29 \%$ pedagang, $14 \%$ PNS dan $14 \%$ anggota Kepolisian. Berdasarkan karakteristik pekerjaan 
ibu, sebanyak $43 \%$ ibu bekerja sebagai petani dan sisanya $(57 \%)$ tidak bekerja.

Berdasarkan hasil wawancara dengan guru dan kepala sekolah SLB Mardi Mulya Kretek mengenai pembelajaran Bina Diri, materi tersebut disampaikan dengan metode pembelajaran ceramah dan demonstrasi. Guru menjelaskan materi pembelajaran di depan kelas kemudian mencontohkan satu sampai dua kali menggunakan model. Ketujuh anak down syndrome mampu mengikuti materi yang diperagakan oleh guru. Namun jika guru hanya memberi instruksi secara lisan maupun tulisan, ketujuh anak tidak mampu menirukan/melakukannya. Sebagai contoh ketika guru memberi instruksi "Mari menggosok gigi!" tanpa diperagakan, anak down syndrome di SLB Mardi Mulya Kretek tidak bisa memahami maksud guru. Anak bisa mengerti apa maksud guru setelah guru memperagakan di depan para anak.

Setelah melakukan wawancara dengan guru SLB Mardi Mulya Kretek mengenai pembelajaran anak down syndrome yang telah dilakukan selama ini, peneliti memberikan perlakuan berupa pembelajaran bina diri dengan metode permainan "Lempar Dadu." Peneliti menyiapkan tiga macam dadu. Pada setiap sisi dadu terdapat instruksi berupa tulisan, gambar kartun dan gambar asli (foto) mengenai Bina Diri atau Merawat Diri. Dadu pertama masing-masing sisinya terdapat instruksi dengan tulisan "Menggosok Gigi”, "Menyapu”, "Mengelap Kaca", "Memotong Kuku", "Mencuci Tangan", dan "Membuang Sampah". Dadu kedua masingmasing sisinya terdapat instruksi dengan gambar kartun "“Menggosok Gigi”, "Menyapu", "Mengelap Kaca", "Memotong Kuku", "Mencuci Tangan", dan "Membuang Sampah". Dadu ketiga masing-masing sisinya terdapat instruksi dengan gambar asli (foto) "Menggosok
Gigi", "Menyapu", "Mengelap Kaca", "Memotong Kuku", "Mencuci Tangan", dan "Membuang Sampah".

Perlakuan permainan ini dilakukan secara acak. Setiap anak diberikan kesempatan masingmasing tiga kali untuk melakukan tiga macam permainan lempar dadu, yaitu dadu dengan instruksi tulisan, dadu dengan instruksi gambar kartun dan dadu dengan instruksi gambar asli. Anak diminta melempar dadu sendiri kemudian anak diminta untuk membaca, menyebutkan instruksi yang terdapat pada sisi dadu tersebut kemudian melakukannya. Setiap anak mempunyai kesempatan yang sama dalam melempar dadu atau dalam melakukan percobaan. Setiap anak melakukan instruksi berbeda sesuai instruksi yang tertera pada dadu yang dilemparkan anak. Adapun hasil dari percobaan dari permainan ini adalah sebagai berikut:

\section{Kemampuan Anak Menerima Instruksi dengan Tulisan}

Tabel 2. Menunjukkan dari tujuh anak yang diberikan perlakuan pertama yaitu instruksi dengan tulisan, hanya dua anak yang mampu menyebutkan instruksi dengan tulisan, yaitu anak $\mathrm{R}$ dan anak Ra. Anak $\mathrm{R}$ mampu menyebutkan instruksi dengan kecepatan sedang pada kesempatan pertama dan ke tiga. Pada kesempatan ke dua anak $\mathrm{R}$ tidak mampu menyebutkan instruksi. Instruksi yang diperoleh anak $\mathrm{R}$ pada kesempatan pertama adalah "Menyapu", dan instruksi yang diperoleh anak R pada kesempatan ketiga adalah "Menggosok Gigi”. Pada kesempatan pertama, anak R mampu menyebutkan kata "Menyapu" karena hanya satu kata. Pada kesempatan ke tiga, anak $\mathrm{R}$ dapat menyebut instruksi "Menggosok Gigi" namun pada awal penyebutan anak hanya menyebut kata "Gigi" kemudian diikuti kata "menggosok". 
Tabel 2. Kemampuan Anak Menerima Instruksi dengan Tulisan Berdasarkan Hasil Perlakuan Permainan Lempar Dadu dengan Instruksi Tulisan

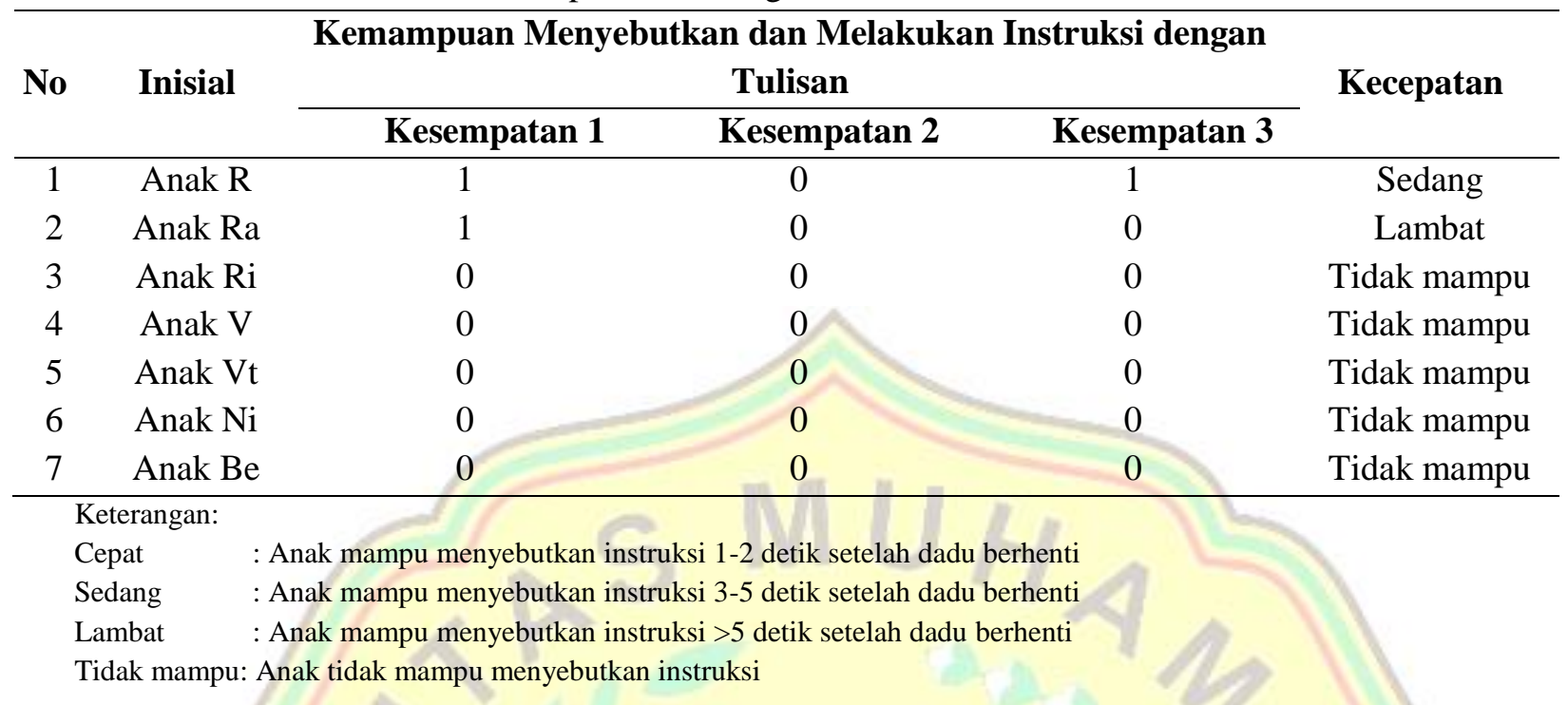

Anak Ra hanya mampu menyebut instruksi pada kesempatan pertama yaitu kata "Menyapu". Pada kesempatan ke dua dan ke tiga terdapat instruksi dengan tulisan "Membuang Sampah" dan "Mengelap Kaca", anak kesulitan dalam menyebutkannya. Dengan demikian dapat disimpulkan bahwa anak masih kesulitan dalam mengeja.

Anak Ri, V, Vt, Ni, dan Be pada kesempatan pertama, ke dua dan ke gita tidak mampu menyebutkan instruksi dengan tulisan di sisi-sisi dadu yang telah dilemparkan. Dengan demikian diambil kesimpulan persentase keberhasilan Permainan Lempar Dadu Instruksi dengan Tulisan sebesar $14,28 \%$.

\section{Kemampuan Anak Menerima Instruksi dengan Gambar Kartun}

Dari tujuh anak down syndrome yang diuji terdapat enam anak yang mampu menyebutkan dan melakukan instruksi dengan gambar kartun kecepatan sedang dan lambat.
Anak $\mathrm{R}$ mampu menyebutkan instruksi dalam gambar kartun pada kesempatan pertama, ke dua dan ke tiga dengan kecepatan sedang. Anak $\mathrm{R}$ membutuhkan beberapa detik untuk mengeja. Anak $\mathrm{Ra}$ mampu menyebutkan instruksi dalam gambar kartun pada kesempatan pertama, ke dua dan ke tiga dengan kecepatan lambat. Anak Ra membutuhkan beberapa detik lebih lama dari anak R untuk mengerja. Anak Ri mampu menyebutkan instrusi dalam gambar kartun pada percobaan pertama, ke dua dan ke tiga dengan kecepatan sedang. Anak Vt mampu menyebutkan instruksi dalam gambar kartun pada kesempatan pertama, ke dua dan ke tiga dengan kecepatan sedang.

Anak V dan Ni mampu menyebutkan instruksi dalam gambar kartun pada kesempatan pertama saja. Pada kesempatan ke dua dan ke tiga anak $\mathrm{V}$ dan $\mathrm{Ni}$ tidak mampu menyebutkan instruksi dalam gambar kartun. Anak Be tidak mampu menyebutkan instruksi dalam gambar kartun pada kesempatan pertama, ke dua dan ke tiga. Hasil selengkapnya seperti pada Tabel 3.

Tabel 3. Kemampuan Anak Menerima Instruksi dengan Gambar Kartun Berdasarkan Hasil Perlakuan berupa Permainan Lempar Dadu dengan Instruksi Gambar Kartun

\begin{tabular}{cccccc}
\hline \multirow{2}{*}{ No. } & Nama & \multicolumn{4}{c}{ Kemampuan Menyebutkan dan Melakukan Instruksi } \\
& & Kesempatan 1 & Kesempatan 2 & Kesempatan 3 & Keterangan \\
\hline 1 & Anak R & 1 & 1 & 1 & Sedang
\end{tabular}




\begin{tabular}{|c|c|c|c|c|c|}
\hline 2 & Anak Ra & 1 & 1 & 1 & Lambat \\
\hline 3 & Anak Ri & 1 & 1 & 1 & Sedang \\
\hline 4 & Anak V & 1 & 0 & 0 & Lambat \\
\hline 5 & Anak Vt & 1 & 1 & 1 & Sedang \\
\hline 6 & Anak Ni & 1 & 0 & 0 & Lambat \\
\hline 7 & Anak Be & 0 & 0 & 0 & Tidak mampu \\
\hline
\end{tabular}

\section{Keterangan:}

Cepat : Anak mampu menyebutkan instruksi 1-2 detik setelah dadu berhenti

Sedang : Anak mampu menyebutkan instruksi 3-5 detik setelah dadu berhenti

Lambat : Anak mampu menyebutkan instruksi $>5$ detik setelah dadu berhenti

Tidak mampu: Anak tidak mampu menyebutkan instruksi

Dengan demikian, disimpulkan bahwa persentase keberhasilan permainan lempar dadu dengan instruksi gambar kartun sebesar $66,67 \%$, lebih besar dari persentase keberhasilan permainan lempar dadu dengan instrusi tulisan $(14,28 \%)$.

\section{Kemampuan Anak Menerima Instruksi dengan Gambar Asli (Foto)}

Tabel 4. Menunjukkan dari tujuh anak down syndrome yang diuji terdapat enam anak yang mampu menyebutkan dan melakukan instruksi dengan gambar asli.

Tabel 4. Kemampuan Anak Menerima Instruksi dengan Gambar Asli (Foto) Berdasarkan Hasil Perlakuan berupa Permainan Lempar Dadu dengan Instruksi Gambar Asli (Foto)

\begin{tabular}{ccccccc}
\hline \multirow{2}{*}{ No. } & \multirow{2}{*}{ Nama } & \multicolumn{3}{c}{$\begin{array}{c}\text { Kemampuan Menyebutkan dan Melakukan Instruksi } \\
\text { dengan Gambar Asli (Foto) }\end{array}$} & \multirow{2}{*}{ Keterangan } \\
\cline { 3 - 5 } & & Kesempatan 1 & Kesempatan 2 & Kesempatan 3 & \\
\hline 1 & Anak R & 1 & 1 & 1 & Cepat \\
2 & Anak Ra & 1 & 1 & 1 & Sedang \\
3 & Anak Ri & 1 & 1 & 1 & Cepat \\
4 & Anak V & 1 & 1 & 1 & Cepat \\
5 & Anak Vt & 1 & 1 & 1 & Cepat \\
6 & Anak Ni & 1 & 1 & 1 & Cepat \\
7 & Anak Be & 1 & 0 & 1 & Lambat \\
\hline
\end{tabular}

Keterangan:

Cepat : Anak mampu menyebutkan instruksi 1-2 detik setelah dadu berhenti

Sedang : : Anak mampu menyebutkan instruksi 3-5 detik setelah dadu berhenti

Lambat : Anak mampu menyebutkan instruksi $>5$ detik setelah dadu berhenti

Tidak mampu: Anak tidak mampu menyebutkan instruksi

Anak R, Ri, V, Vt, Ni mampu menyebutkan dan melakukan instruksi dalam gambar asli (foto) pada kesempatan pertama, ke dua dan ke tiga dengan kecepatan 1-2 detik setelah dadu berhenti (cepat). Anak Ra mampu menyebutkan dan melakukan instruksi dalam gambar asli (foto) pada kesempatan pertama, ke dua dan ke tiga dengan kecepatan sedang (3-5 detik setelah dadu berhenti). Anak Be mampu menyebutkan dan melakukan instruksi dalam gambar asli (foto) pada kesempatan pertama dan ke tiga, namun gagal pada kesempatan kedua. Dengan demikian dapat disimpulkan persentase keberhasilan permainan lempar dadu dengan instruksi gambar asli (foto) sebesar $\quad 95,23 \%$ paling tinggi dibanding keberhasilan permainan lempar dadu dengan instruksi tulisan $(14,28 \%)$ dan gambar kartun $(66,67 \%)$.

\section{Pembahasan}

Penelitian permainan lempar dadu sebagai media pembelajaran bina diri pada anak down syndrome menunjukkan hasil bahwa permainan lempar dadu dengan instruksi gambar asli (foto) memberikan kemampuan anak menyebutkan dan melakukan instruksi dengan persentase 
keberhasilan paling tinggi $(95,23 \%)$ dibanding keberhasilan permainan lempar dadu dengan instruksi tulisan $(14,28 \%)$ dan gambar kartun $(66,67 \%)$.

Anak down syndrome merupakan pembelajar secara visual. Anak memiliki kesadaran visual dan kemampuan visual yang baik. Penggunaan gambar, dan bagan akan lebih mempermudah anak dalam pembelajaran. Pemanfaatan pembelajaran visual dapat diterapkan dalam berbagai aspek termasuk kemampuan akademik, rutinitas kelas, dan pembentuk tingkah laku. Anak tunagrahita (down syndrome) sedang dapat mengurus diri sendiri tanpa tergantung pada orang lain ${ }^{5}$. Dalam kurikulum Pendidikan Luar Biasa $^{8}$ disebutkan bahwa kemampuan merawat diri merupakan mata pelajaran yang harus diberikan kepada siswa tunagrahita sedang (down syndrome) mengingat keterbatasan kemampuan anak. Anak down syndrome masih memiliki potensi diberikan latihan mengurus diri dalam hal ketrampilan membersihkan diri, berhias, menghindari bahaya agar anak dapat mandiri tanpa tergantung pada orang lain.

Hasil penelitian ini menunjukkan bahwa metode permainan dadu bisa dijadikan alternatif metode pembelajaran bina diri kesehatan bagi anak down syndrome dan nantinya dapat dilakukan secara berulang-ulang oleh guru agar anak terbiasa melakukan aktivitas merawat dirinya tanpa tergantung orang lain. Metode pembelajaran dengan permainan lempar dadu ini dapat diterapkan untuk melengkapi metode pembelajaran lain seperti metode drill. Sesuai dengan hasil penelitian oleh Adnyani, dkk tahun 2015 yang menunjukkan bahwa ada pengaruh metode pembelajaran drill (latihan berulangulang) terhadap kemampuan merawat diri sendiri pada anak tunagrahita siswa kelas I SLB C 1 Negeri Denpasar ${ }^{9}$. Hasil penelitian oleh Jaelani tahun 2013 juga sejalan dengan hasil penelitian ini. Ada pengaruh metode drill (latihan berulangulang) dengan media video terhadap keterampilan bina diri menggosok gigi pada anak tunagrahita ringan ${ }^{10}$. Penelitian oleh Rahayu tahun 2000 menyebutkan bahwa anak tunagrahita yang sangat membutuhkan latihan menyisir rambut dan menggosok gigi adalah anak tuna grahita mampu latih ${ }^{11}$. Hasil penelitian ini juga didukung oleh hasil penelitian Wahyuni tahun 2013 yang menunjukkan bahwa ada pengaruh kemampuan merawat diri anak tunagrahita ringan melalui pembelajaran langsung saat menstruasi terhadap pemakaian pembalut. Permainan lempar dadu dalam penelitian ini diberikan secara langsung kepada anak down syndrome. Dengan pembelajaran yang diberikan secara langsung, anak mendapatkan kesempatan dan langsung mendapatkan bimbingan dari pemberi materi ${ }^{12}$.

Sesuai dengan teori behavioristik yang menyebutkan bahwa belajar merupakan perubahan tingkah laku akibat dari adanya interaksi antara stimulus dan respon. Seseorang dianggap telah belajar sesuatu apabila mampu menunjukkan perubahan tingkah laku. Perubahan tingkah laku merupakan hasil interaksi antara stimulu dan respon. Proses pembelajaran hendaknya diatur sedeikian rupa sehingga benarbenar menarik dan dapat menimbulkan motivasi belajar siswa. Permainan dadu dengan instruksi berupa tulisan, gambar kartun dan gambar asli (foto) dinilai cukup menarik badi anak down syndrome dan mampu menummbuhkan motivasi anak untuk mempelajari ketrampilan yang akan ${ }^{13}$.

Anak down syndrome merupakan anak yang mempunyai intelegensia di bawah rata-rata sehingga mempunyai hambatan/gangguan dalam menyesuaikan diri dengan tuntutan yang berlaku di masyarakat dan memerlukan program pendidikan khusus. Pembelajaran kepada anak tunagrahita atau down syndrome memerlukan kesabaran, teknik dan perlakuan khusus. Materi pembelajaran dipilih yang mendasar dan sering dilakukan dalam kehidupan sehari-hari sehingga lebih mudah diterima oleh anak. Pembelajaran bina diri dalam hal ini merawat diri sendiri lebih bermakna bagi anak down syndrome karena anak mendapat bekal keterampilan hidup dan anak dapat diterima sebagai bagian dari kehidupan keluarga dan masyarakat, tanpa tergantung penuh pada orang lain ${ }^{3,13}$.

\section{KESIMPULAN DAN SARAN}

Metode permainan lempar dadu ini dapat meningkatkan kemampuan anak down Syndrome dalam melakukan bina diri atau merawat diri 
sendiri. Dadu dengan gambar atau foto asli mempunyai pengaruh yang lebih untuk meningkatkan kemampuan anak down syndrome melakukan bina diri. Disarankan kepada guru dalam memberikan pembelajaran bina diri pada anak down syndrome hendaknya mampu memilih metode yang sesuai karakteristik anak, salahsatunya adalah metode permainan lempar dadu. Kepada peneliti selanjutnya disarankan untuk mmelakukan penelitian eksperimental dengan menyertakan kelompok kontrol, sampel lebih besar dan analisis data yang sesuai untuk jenis penelitian eksperimen.

\section{DAFTAR PUSTAKA}

Reynolds, 2003. Down's Syndrome Screening is Unethical: Views of Today's Research Ethics Committees. J.Clin Pathol. 2003, April, 56 (4): 268-70

Rosida L., Roselina P, 2006. Gambaran Dermatoglifi pada Penderita Sindrom Down di Banjarmasin dan Martapura Kalimantan Selatan. Jurnal Anatomi Indonesia. 2 Desember 2006. Vol. 1. Hal. 71-78

Bukley S, Bird G, Sacsks B, Archer T, 2002. The Achievement of Teenagers with Down Syndrome. Down Syndrome News and Updates Vol.2. Issue 2 (3);90-96

Leonita C., Nina S., 2015. Web untuk Deteksi Dini Tingkat Retardasi Down Syndrome pada Anak. Jurnal Teknik Informatika dan Sistem Informasi. 1 April 2015. Vol. 1. Hal. 1

Maria JW, 2007. Pengembangan Kemandirian Anak Tunagrahita Mampu Latih. Bandung: Depdiknas

Dantes N, 2012. Metode Penelitian. Yogyakarta: Andi Offset.

Juang S, 2005. Pengantar Penelitian dengan Subjek Tunggal. Bandung: UPI PRESS
Dirjen Dikti Depdiknas, 1991. Peraturan Pemerintah RI Nomor 72 Tahun 1991 tentang Pendidikan Luar Biasa. Jakarta: Depdikbud

Adnyani DN, Suarni NK, Jampel IN, 2015. Pengaruh metode Drill terhadap Motivasi Belajar dan Kemampuan Merawat Diri Sendiri bagi Anak Tunagragita pada Pelajaran Bina Diri Siswa Kelas I SLB C1 negeri Denpasar Tahun pelajaran 2014/2015. E-Journal Program pascasarjana Universitas pendidikan Ganesha Program Studi Penelitian dan Evaluasi Pendidikan. Vol. 5, No. 1 Tahun 2015

Jaelani BM, 2013. Metode Drill Bermedia Video terhadap Keterampilan Bina Diri Anak Tunagrahita ringan, diambil dari http://www.scribd.com/doc/197719290

Rahayu E, 2000. Kemampuan Merawat Diri pada Tunagrahita. Staf Pengajar Fakultas Psikologi UNIKA Sugiyopranoto Semarang

Wahyuni IK, 2013. Pengaruh Pembelajaran langsung saat Menstruasi untuk meninngkatkan Kemampuan Merawat Diri Siswa Tunagrahita Ringan di SLB. Jurnal Pendidikan Khusus Universitas Negeri Surabaya Tahun 2013. Halaman 8-9.

Djamarah dan Zain A, 2002. Strategi Belajar Mengajar. Jakarta: Rieneka Cipta.

Hasanah, NU, Wibowo H, Humaedi S, 2015, Pola Pengasuhan Orang Tua dalam Upaya Pembentukan Kemandirian Anak Down Syndrome. Share Social Work Jurnal. Juli 2015. Vo.5 No.1. Hal.65-70 